assuming that there is a single absurdity implied by every false proposition. But when this last criticism is taken seriously, even the popular 'minimal' logic of Johansson seems to embody a non-constructive form of reasoning.

Of course, given the apparatus of quantification over counteraxioms in the object language, we can formulate a generalized absurd proposition $\exists x G(x)$, and use it to define a new negation operator by the schema

$$
\neg_{\mathrm{j}} P={ }_{\mathrm{df}}(P \supset \exists x G(x)) .
$$

The new negation so defined can be shown, using only constructive positive logic, to obey the rules of Johansson's logic; but $\neg_{j} P$ is a weaker and less informative statement that $\neg P .^{1}$

University of Melbourne

Parkville, Victoria 3052, Australia allen_hazen@muwayf.unimelb.edu.au

1 These reflections were occasioned by reading J. M. Dunn's penetrating study of the semantics of negation, 'Star and perp', in J. Tomberlin, ed. Philosophical Perspectives Vol. 7: Language and Logic (Atascadero CA 1993). I presented completeness proofs for the logic of subminimal negation in a technical report, 'Subminimal negation', University of Melbourne Philosophy Department Preprint 1/92 (June 1992).

\title{
Velleman on intentions as reasons for action
}

\section{GideON YAFFE}

Let's suppose that I form an intention to, say, go bowling. Does the fact that I have an intention to go give me a reason to go beyond the reasons which I had for forming the intention in the first place? J. David Velleman is one person who thinks so. In addition, Velleman has recently presented a theory of practical reasoning under which practical reasoning is a species of theoretical reasoning. (J. David Velleman, Practical Reflection, Princeton: Princeton University Press, 1989.) Under the theory, intentions are certain special sets of beliefs. It appears that unless Velleman denies Hume's claim that beliefs, unlike desires, give us no reason to act, he is attempting to embrace a contradiction: how could it be that intentions give reasons for action, beliefs do not give reason for action, and yet intentions 
are sets of beliefs? ${ }^{1}$ Velleman has attempted to avoid this difficulty by arguing that the beliefs which, in certain circumstances, make up our intentions are not themselves reason-giving, but rather interact with our desires in such a way as to give us reason to act.

Michael Bratman has attacked this view by arguing that under Velleman's theory of why intentions give reasons for action, many other mental states will give reasons for action in the same way. (Michael E. Bratman, 'Cognitivism about practical reason', Ethics 102, 1991, pp. 117-28.) Paraphrasing Bratman, the way in which intentions give reasons for action under Velleman's view is promiscuous, making many other states of mind that are far different from intention - and which we do not usually consider to give us reason to act - reason-giving in the same way. (Bratman, p. 126)

I will argue that Bratman's criticism arises out of a misreading of Velleman, and, further, Velleman's theory gives an account of how intentions give reasons for action which is monogamous; under Velleman's theory, intentions give reasons for action in a way in which no other mental states do. It is also the case, however, that under Velleman's theory some peculiar mental states that are rather different from intentions also give reason for action. This fact presents Velleman with a challenge: he must give us some reason why it is that intentions play the central role in practical reasoning that these other, odd states of mind do not. Velleman has an explanation available to him, and, as I hope to show, the explanation lends insight into what exactly Velleman means when he says that practical reasoning is a species of theoretical reasoning.

Under Velleman's theory, we all have a desire for self-knowledge which is satisfied (although not exhausted) when it turns out that a belief which we have about our current or future conduct is true. ${ }^{2}$ So, if I believe that I will go bowling, and then I do, in acting I satisfy my desire for self-knowledge by turning a mere belief about myself into knowledge. Therefore, expectations about what I will do - that is, beliefs of the form 'I will $A$ ' provide reason for action, for by acting as I expect I will satisfy my desire for self-knowledge.

So, under Velleman's view intentions are some complex of expectations,

1 Throughout this paper I am assuming that any motive for acting provides a reason for acting. This Humean account of motivation is not uncontroversial, but I will not be discussing its merits and demerits here.

2 Velleman analyses the desire for self-knowledge into two separate desires: a desire for self-awareness (the desire to know what it is that I am doing or will do) and a desire for self-understanding (the desire to know why it is that I am doing what I am doing). This division in the desire for self-knowledge does not play a significant role in Velleman's theory as to how intentions give reasons for action. 
but we have yet to specify what complex Velleman takes them to be. Under Bratman's reading of Velleman, intentions are not merely expectations of the form 'I will $A$ ', they consist of a further self-referential element. He sees an intention as consisting, under Velleman's view, of a belief with the following content: 'I will $A$ as a result of this very belief.' Further, for this self-referential belief to constitute an intention, I must have an antecedent desire to $A$ which is strong enough that my additional expectation that I will $A$, in conjunction with my desire for self-knowledge, will provide enough of a push that $A$-ing will be that of my alternative actions which I most desire. This further condition constitutes the context in which my self-referential expectation must occur in order for it to be an intention. ( $A$ ing might not have been that of my options which I most desired before I formed the expectation that I would $A$, but that expectation itself gives me an additional reason to $A$.)

Bratman uses an example to argue that, under Velleman's theory, intentions are reason-giving in the same way that many other, significantly different, mental states are. The example is built on Derek Parfit and Gilbert Harman's insomniac example:

A pessimistic actor might be on stage with the purportedly self-fulfilling belief that (a) I will stumble on my next lines as a result of this very belief. This belief that (a) puts the actor 'into a position to increase his self-knowledge by satisfying that very belief.' After all, if he does stumble on his lines as a result of his belief that $(\mathrm{a})$, this will be as he expects. (Bratman, p. 126)

The idea is that under Velleman's theory the actor's belief gives him a reason to act in exactly the same way that my intention to go bowling gives me reason to go; and that seems wrong.

I agree with Bratman that this would be an unacceptable consequence; I disagree that it actually is a consequence of Velleman's view. Bratman quotes Velleman as saying that

the belief constituting an intention puts us in a position to increase our self-knowledge by satisfying that very belief. The content of this belief therefore provides us with a reason for acting. (Bratman, p. 125: quoted from Velleman, p. 200)

Since Bratman sees the content of the belief about which Velleman is speaking as being 'I will $A$ as a result of this very belief' he sees no difference between the content of the actor's belief and the content of an intention. However, Bratman recognizes that the actor's belief is not, according to Velleman's theory, an intention, for it does not occur in the necessary contextual conditions. In particular, the actor has no antecedent desire to stumble on his lines, and hence, even given his desire for self- 
knowledge and his expectation that he will stumble, stumbling is not the most attractive of his options.

This analysis of the actor example, I believe, is based on a misreading of Velleman. Under Velleman's theory, the difference between the case of the actor and that of the person who genuinely intends is a difference in the actual content of the belief, not just in the context of occurrence of the belief. Further, as I will argue, the content of the belief which constitutes an intention provides a reason for action in a way that the actor's belief does not.

What do I take to be the content of the belief which constitutes an intention under Velleman's view? Velleman says,

I have identified intentions with self-fulfilling expectations that are motivated by a desire for their fulfillment and that represent themselves as such. (Velleman, p. 109)

I take this to mean that my intention to $A$ is the following series of beliefs:

(1) My belief that I will $A$.

(2) My belief that my $A$-ing will result, in part, from (1).

(3) My belief that my $A$-ing will be brought about by the strength of the combination of my antecedent desire to $A$ and my desire to act as I expect I will. . $^{3,4}$

There is also a contextual element which makes this series of beliefs into an intention: I desire self-knowledge - I desire to act as I expect I will - and

3 Concerning (3), Velleman says, for instance,

$[\mathrm{W}]$ hen an agent forms an intention, he normally regards it as a manifestation of his motives for acting. For in order to regard the intention as his intention, he has to regard it, not as a product of extraneous forces or as a mere psychological glitch, but as an expression of his desires. And the desires that he regards his intention as expressing are his motives for performing the intended action.

(Velleman, p. 98)

What could it mean for the desire to be expressed in the intention if the content of the intention included only an expectation that the agent would perform the action without any reference at all to the way in which the desire for its performance contributes to its performance? Under Bratman's reading of Velleman the content of the intention contains no reference at all to the agent's desire to perform the action, but then Bratman's account fails to make sense of Velleman's claim that the intention itself expresses the agent's desire.

4 The three beliefs could be formed into a single conjunctive belief. Velleman often states the content of an intention as a single belief, and when he does so, I believe he is trying to pack these three beliefs into one. For instance, he says, '[T]he content of an intention to act can be formulated most clearly as "This is a successful intention to act."'(Velleman, p. 200) This formulation of the content of an intention is slightly misleading for it makes it seem that it does not contain (3). If this is the case, then I 
that desire plus my expectations (that is, (1)-(3)) will together make $A$ that of my alternative actions which I most desire. ${ }^{5}$ These conditions do not constitute the intention, but they are required for the series of beliefs to be an intention. ${ }^{6}$

Because of my desire for self-knowledge, (1), (2) and (3) each give slightly different reasons for acting. If any one of them turns out to be true, then I have gained some self-knowledge, which I desire. (1) will turn out to be true whenever I $A$, even if I am forced to $A$ by something outside of me (an electric shock, for instance). However, I can also make (1) true by $A$ ing normally. (2) and (3) will not be true if I do not $A$, but $A$-ing will not necessarily be enough to make them true. If I $A$ because I am forced to by something external to myself, then I have not done so even in part because of (1); hence, in such a circumstance (2) will not be made true by my conduct. Similarly, if I am forced or coerced into $A$-ing, then it will not be the strength of my antecedent desire to $A$ combined with my desire for selfknowledge that brought about my $A$-ing. (2) and (3) specify how I should $A$ if I am to maximize the amount of self-knowledge which I can gain by $A$-ing. An intention, then, will give reason for action triply, for it gives three different ways in which acting will supply self-knowledge, something we desire.

The actor's belief that he will stumble on his lines because of that very belief seems to satisfy (1) and (2). He does believe that he will stumble on his lines, and he does believe that he will do so as a result of his belief that he will. He does not, however, believe that his stumbling will be brought about by his antecedent desire to stumble (combined with his desire for

believe that Velleman slips on his own formulation of an intention. A more sympathetic reading, however, sees the notion of the intention being successful as contingent on the action being - taking into consideration both the antecedent desire to act as well as the desire for self -knowledge - the most desired of the possible alternative actions. Hence the belief that the intention will be successful is a belief that the action will be brought about by the strength of the combination of desires.

5 It should be noted that the contextual conditions are such that (3) can only ever turn out to be a true belief if the contextual conditions are satisfied. This fact plays an important role in the account, as we shall see.

6 The way that I have drawn out Velleman's view of intentions is in line with his description of intentions as follows: Given the contextual conditions, (1), (2) and (3) are self-fulfilling expectations, for they engage with my desire for self-knowledge in such a way as to make $A$-ing the most attractive of my options. They are motivated out of a desire for their fulfillment, for I have an antecedent desire to $A$ and a desire for self-knowledge. Finally, they represent themselves as such self-fulfilling expectations that are so motivated, for the content of (2) and (3) specify why (1) is self-fulfilling and how it is motivated by a desire for its fulfillment. 
self-knowledge), for he has no such desire. Hence, he gains reason to stumble on his lines from (1) and from (2), but not from (3), since he holds no belief like (3). Therefore, Bratman's claim that the actor has the same reason for acting which anyone who had an intention would have is incorrect, for although the actor has some reasons for stumbling, if he actually intended to stumble he would have greater reason to do so.

Bratman's actor example was intended to be an example of an agent who holds the same beliefs as the person who intends, but lacks an intention because he fails to satisfy the required contextual conditions. Such a person would have exactly the same sort of reason for action as the person who intends, and this fact would suggest promiscuity in Velleman's view. We have seen that Bratman's actor example fails to establish this promiscuity. We might think, however, that we could find an alternative example under which an agent satisfied (1), (2) and (3) but failed to satisfy the contextual conditions, and therefore failed to intend, but still was given reason to act from each of (1), (2) and (3). Such an example would establish the promiscuity in Velleman's view as Bratman desires. However, I believe that no such example could be constructed. Let me elaborate.

Bratman's actor example shows that an agent could hold beliefs (1) and (2), fail to intend, and still gain reason for acting from each of (1) and (2). But could an agent hold the belief specified in (3), fail to satisfy the contextual conditions, and still gain a reason to act from (3)? No, for (3) gives the agent a reason to act only if in acting the agent makes (3) true, and hence gains self-knowledge. But, if the agent fails to satisfy the contextual conditions, then there must be some other action, call it $B$, which the agent desires more (all things considered) than she desires $A$ (taking into account her antecedent desire to $A$ and her desire for self-knowledge). But if this is the case, then when the agent $A$ 's she does not make ( 3 ) true, for her $A$-ing will not be brought about by the strength of the combination of her antecedent desire to $A$ and her desire for self-knowledge, for her desire to $B$ is stronger. The agent believes that her action will be brought about by the strength of the combined desire to $A$, but there is no way that this belief can be made true by her conduct unless the contextual conditions are satisfied. Hence the agent who fails to satisfy the contextual conditions is not actually given a reason to $A$ from (3), for $A$-ing will not make (3) true. ${ }^{7,8}$

Although, under Velleman's theory, there cannot be examples of mental states different from intention which give exactly the same sorts of reason

7 Another way to make this point is by way of the following example: Imagine a selfdeceived actor who holds (1) through (3) and therefore takes his desire to stumble when combined with his desire for self-knowledge to be the strongest of his desires when in fact he is wrong: in fact there is some alternative action which he desires more. Stumbling, however, would not make (3) true, in the case of the self-deceived 
to act as intentions give, there are mental states which give reasons to act which are quite similar to the reasons for action given by an intention. For instance, imagine that Bratman's actor has the self-referential belief that Bratman suggests, and further he has a self-destructive desire to actually stumble on his lines. He is aware of this desire and thinks that it will contribute to his stumbling on his lines (maybe because it will make him so nervous), but he also knows that his desire to give his speech without stumbling is stronger. So, he satisfies each of conditions (1) and (2), and he also has a third relevant expectation: he believes that his stumbling will result in part from his desire to stumble. Although this self-destructive actor lacks an intention to stumble - his third expectation is not the same as that specified in (3), nor does he satisfy the necessary contextual conditions - he has a reason to stumble which is analogous to, although not the same, as that of the actor who intends to stumble.

This example does not show that Velleman's theory of why intentions give reasons for action is promiscuous, for the self-destructive actor does not have exactly the same reason to stumble as the person who intends. Rather, it shows that under Velleman's theory there are some very peculiar mental states which give us reason to act in a way quite similar to the way in which intentions give us reason to act. This amounts to a criticism of Velleman's view only if he provides no explanation for why it is that intentions play the crucial role in our practical reasoning that they play, while states of mind like that of the self-destructive actor play no significant role at all. For instance, if both the self-destructive actor's state of mind and the state of mind of intention are similarly reason-giving, why is it that we form intentions as conclusions in practical reasoning, and not states of mind like that of the self-destructive actor?

actor, for the belief could only be made true if the action is brought about by the strength of the combination of the actor's antecedent desire to $A$ and his desire to do what he expects; by supposition, the self-deceived actor's desire to stumble is not actually the strongest of his desires, no matter what he thinks. Hence, the selfdeceived actor does not truly gain a reason to stumble from (3) unless he satisfies the contextual conditions.

8 We could construct a story in which the strength of my antecedent desire to $A$ when combined with my desire for self-knowledge brought about my $A$-ing, but in a deviant way. Perhaps a mad scientist forces me to $A$ if and only if he finds that my all things considered desire to $A$ is the strongest of my desires. This will create something of a problem for Velleman's view for it is generally - although not always - the case that we would prefer to have our desires bring about our actions normally than for them to bring about our actions by way of the antics of mad scientists. But why should this be the case if our desires are equally satisfied in either case? Almost all theories of intention encounter some difficulties in cases involving deviant causal chains. In that way, this challenge is not aimed uniquely at Velleman's theory. 
A possible explanation is this: Intentions are, by their very structure, uniquely designed to lead us (after they are formed) to act as we most desire. We form an intention to $A$, and, in part as a result of that fact, $A$ ing becomes that of our alternative actions which we most desire. No other state of mind, as we have seen, guarantees that that which it gives us reason to do is also that which we most desire to do. Therefore it is clear why intentions play the prominent role in our practical reasoning that they do, while other reason-giving states of mind do not: practical reasoning is an activity in which we engage in order to develop the best possible strategies for the satisfaction of our desires. Intentions are far better tools for performing that function than states of mind like that of the self-destructive actor, because if the self-destructive actor does what his state of mind gives him reason to do, he will not satisfy his desires in the best way possible. And, as a result of the structure of intentions, no reason-giving state of mind different from intention will direct us to do that which we most desire to do, all things considered.

This explanation relies on the claim that the central goal of practical reasoning is the production of useful strategies for the satisfaction of our desires. Can Velleman embrace this largely undisputed claim? He cannot if it amounts to denying what he most hopes to establish: that practical reasoning is a species of theoretical reasoning. Interestingly, this claim of Velleman's can be interpreted in such a way that it is compatible with the claim that the goal of practical reasoning is the satisfaction of our desires, as long as we allow - as Velleman asks us to - that one of the central desires that we are interested in satisfying is our desire for self-knowledge. The central goal of practical reasoning, under such an interpretation, is indeed the production of useful strategies for satisfying our desires; however, since our most pervasive desire is the desire for self-knowledge - that desire is, perhaps, the only single desire which is engaged in every particular instance of practical reasoning - this goal is in large part the goal of gaining knowledge of ourselves. It is this sense in which a primary goal of practical reasoning is the production of true beliefs. Under such an interpretation of Velleman's theory, the claim that practical reasoning is a species of theoretical reasoning is not incompatible with the claim that practical reasoning is aimed at the satisfaction of our desires. ${ }^{9}$

Early in this paper I claimed that the way in which intentions give reason for action, under Velleman's view, is monogamous; what we have seen is

9 This does not appear to be an unfair characterization of Velleman's view, although I am not certain whether it is precisely what he intended. Consider the following:

[T]o me being an agent is not a neutral capacity for pursuit; it is a substantive commitment to a particular, second-order pursuit, that of knowing about one's own pursuits. (Velleman, p. 207) 
that, under the theory, intentions are actually doubly monogamous. No other state of mind gives us reason to act as our intentions do, and, no other state of mind can play the role in practical reasoning which our intentions play. This follows from the fact that only intentions support the intricate goal of practical reasoning: the production of strategies which help us to satisfy our desires, and - as an essential part of that process lead us to produce as many true beliefs about ourselves as possible. In Velleman's theory, the structure of intentions links them to this complicated goal in a way that no other state of mind could be, or should be, linked. ${ }^{10}$

Stanford University

Stanford, CA 94305, USA

yaffe@csli.stanford.edu

He seems to suggest that the defining characteristic of agency - in so far as agency is defined as the ability to reason practically - is the dedication to such a second-order pursuit. Under such a view, the aim of practical reasoning is the success of our pursuits, it just so happens that the one pursuit in which we are always engaged is the pursuit of self-knowledge.

Then later,

When we deliberate, we mostly experiment with various descriptions of the alternatives, of their attractions, of ourselves, and of our futures, seeking that combination of action, motive, character and plan which would make our lives most amenable to explanation and prediction. (Velleman, p. 258)

Here it appears that deliberation is aimed at explanation and prediction, but given that we know that Velleman sees us as having a deep and pervasive desire for the kind of explanation and prediction under discussion, this characterization of practical reasoning does not preclude its focus on the satisfaction of our desires.

My interpretation of Velleman's claim that practical reasoning is a species of theoretical reasoning is never explicitly confirmed by the text. However, the interpretation is not contradicted in the text and it appears to be the only interpretation under which Velleman can hold onto his claim that practical reasoning is a species of theoretical reasoning and at the same time account for the central role of intention (as opposed to other similar reason-giving states of mind) in our practical reasoning.

${ }^{10}$ Special thanks to Michael Bratman for his patience and encouragement, as well as his insightful comments on a number of earlier drafts of this paper. 